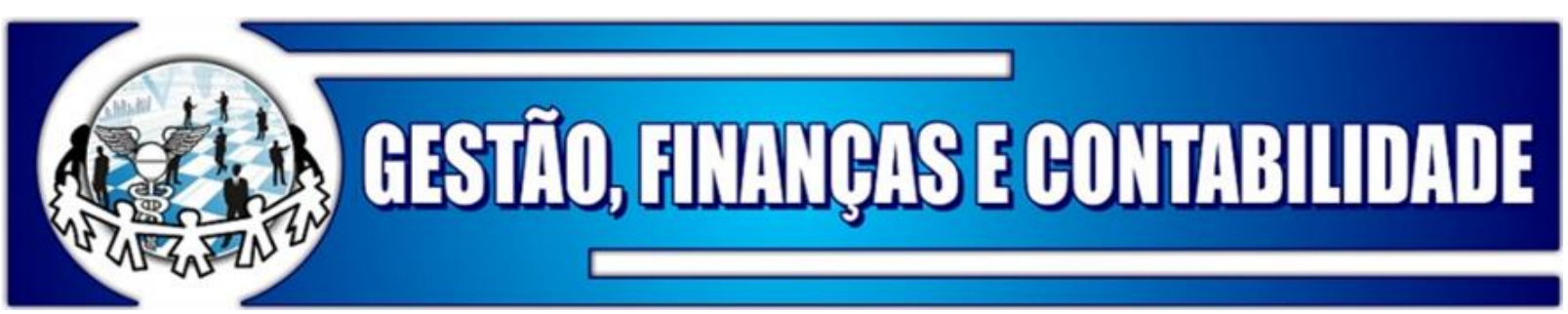

\title{
RELAÇÃO ENTRE REMUNERAÇÃO DOS EXECUTIVO E O DESEMPENHO ECONÔMICO E FINANCEIRO EM EMPRESAS BRASILEIRAS
}

\section{RELATIONSHIP BETWEEN EXECUTIVE REMUNERATION AND ECONOMIC AND FINANCIAL PERFORMANCE IN BRAZILIAN COMPANIES}

\section{RELACIÓN ENTRE REMUNERACIÓN DE LOS EJECUTIVOS Y EL DESEMPEÑO ECONÓMICO Y FINANCIERO EN EMPRESAS BRASILEÑAS}

\begin{abstract}
Maurício Leite
https://orcid.org/0000-0001-7764-3969

Mestre em Ciências Contábeis pela Universidade Regional de Blumenau (PPGCC/FURB)
\end{abstract}

E-mail: mauricio.leite@ymail.com

Nelson Hein

https://orcid.org/0000-0002-8350-9480

Professor do Programa de Pós-Graduação em Ciências Contábeis e Administração (FURB) Doutor em Engenharia de Produção pela Universidade Federal de Santa Catarina (UFSC)

E-mail: hein@furb.br

\section{RESUMO}

Este estudo objetivou analisar a relação entre a remuneração dos executivos e o desempenho econômico e financeiro em empresas brasileiras. Realizou-se pesquisa descritiva, com abordagem quantitativa e análise documental. A população da pesquisa compreendeu as empresas listadas no IBrX50. A amostra abrangeu 36 empresas, tendo como período de análise entre os anos de 2012 e 2017, totalizando 216 observações. Os resultados demonstraram quea remuneração fixa (RFX) possui relação negativa com o desempenho econômico e financeiro, enquanto a remuneração variável de curto prazo (RVCP) e total (RMT) apresentaram relação positiva. Já a remuneração variável de longo prazo (RVLP) apresentou relação positiva estatisticamente não significativa. Por meio da regressão quadrática, demonstrou-se que os componentes da remuneração executiva apresentam relação positiva e significativa, com exceção da remuneração total (RMT),com o desempenho econômico e financeiro até um ponto ótimo de desempenho. A partir deste ponto ótimo, o desempenho econômico e financeiro torna-se decrescente.

Palavras-chave: Remuneração dos executivos. Desempenho Econômico. Desempenho Financeiro. DP 2 . Regressão Quadrática.

\section{ABSTRACT}


Leite e Hein (2019)

Relação entre Remuneração dos Executivo e o Desempenho

Econômico e Financeiro em Empresas Brasileiras

This study aimed to analyze the relationship between executive compensation and economic and financial performance in Brazilian companies. Descriptive research was carried out, with a quantitative approach and documentary analysis. The research population comprised the companies listed on the IBrX50. The sample include 36 companies, with the period of analysis between the years 2012 and 2017, totaling 216 observations. The results showed that fixed remuneration (RFX) has a negative relationship with economic and financial performance, while short-term (RVCP) and total variable remuneration (RMT) showed a positive relationship. Long-term variable remuneration (RVLP), on the other hand, presented a statistically non-significant positive relationship. Through quadratic regression, it was demonstrated that the components of executive remuneration have a positive and significant relationship, with the exception of total remuneration (RMT), with economic and financial performance to an optimum point of performance. From this optimum point, the economic and financial performance becomes decreasing.

Keywords: Remuneration of executives. Economic Performance. Financial Performance. DP2. Quadratic Regression.

\section{RESUMEN}

Este estudio tuvo como objetivo analizar la relación entre la compensación ejecutiva y el desempeño económico y financiero en las empresas brasileñas. Se realizó una investigación descriptiva, con un enfoque cuantitativo y análisis documental. La población de investigación comprendía las empresas que figuran en el IBrX50. La muestra incluyó 36 empresas, con el período de análisis entre los años 2012 y 2017, totalizando 216 observaciones.Los resultados mostraron que la remuneración fija (RFX) tiene una relación negativa con el desempeño económico y financiero, mientras que la remuneración variable a corto plazo (RVCP) y la remuneración total (RMT) mostraron una relación positiva. La remuneración variable a largo plazo (RVLP), por otro lado, presentó una relación positiva estadísticamente no significativa. A través de la regresión cuadrática, se demostró que los componentes de la remuneración ejecutiva tienen una relación positiva y significativa, con la excepción de la remuneración total (RMT), con un desempeño económico y financiero hasta un punto óptimo de desempeño. Desde este punto óptimo, el desempeño económico y financiero disminuye.

Palabras clave: Remuneración de los ejecutivos. Desempeño Económico. Rendimiento Financiero. DP2. Regresión cuadrática.

\section{INTRODUÇÃO}

A literatura sobre remuneração dos executivos datam da década de 1970, tendo sua rápida aceleração na década de 1990 (EDMANS; GABAIX; JENTER, 2017). Tinoco, Rossi e Portugal (2015) chamam a atenção para os altos valores pagos aos executivos à título de remuneração, mesmo quando apresentam resultados financeiros insatisfatórios. Tal assertiva justifica o despertar e aceleração do interesse sobre a temática tanto em âmbito internacional e nacional.Conforme Souza, Cardoso e Vieira (2017), associa-se o sistema de remuneração dos executivos à ferramenta que minimiza o problema de agência. Tinoco et al. (2015) pontuam que a remuneração e outros incentivos não financeiros contribuem para alinhar os interesses dos acionistas e gestores, direcionando-osa decisões que visam melhorar o desempenho econômico e financeiro da empresa.

Aguiar e Pimentel (2017) sugerem que à medida que as empresas definem seus objetivos de curto e longo prazos, se ajustam as políticas de remuneração, dando pesos à cada componente da remuneração. Como respostas, as empresas oferecerem níveis de remuneração mais elevados quando obtêm desempenho superiores. Nesta mesma linha de considerações, 
Leite e Hein (2019)

Relação entre Remuneração dos Executivo e o Desempenho

Econômico e Financeiro em Empresas Brasileiras

Konrath, Lunkes, Gasparetto e Schnorrenberger (2018) entendem que quanto maior for, percentualmente, a remuneração baseada no desempenho, maior será a dependência da remuneração do alcance dessas metas estabelecidas pela organização.

Edmans et al. (2017) destacam que, apesar de décadas de pesquisa acerca da remuneração dos executivos, há muitas questões em aberto, citando por exemplo, aefetiva implicação da remuneração sobre o desempenho das organizações. SegundoNascimento, Barbosa Neto, Cunha e Dias (2013), Silva e Chien(2013) e Souza et al. (2017), resultados de pesquisas anteriores são ambíguas, uma vez que alguns estudos encontraram relação positiva entre remuneração e desempenho e outros encontraram resultados opostos. Assim, não há consenso sobre o alinhamento entre os planos de remuneração e os conflitos de agência, tornando o tema um campo importante de pesquisa.

Neste contexto, o presente estudo busca contribuir para o avanço do conhecimento acerca do tema, respondendo a seguinte questão problema: qual a relação entre a remuneração dos executivos e o desempenho econômico e financeiro em empresas brasileiras? Visando responder à esta questão, tem-se por objetivo analisar a relação entre a remuneração dos executivos e o desempenho econômico e financeiros em empresas brasileiras.

A propósito, Oberholzer e Barnard (2015) pontuam que há uma variedade de medidas de mensuração de desempenho, sendo elas medidas financeiras e não financeiras, e medidas de desempenho baseado em números contábeis. A esse respeito, Konraht et al. (2018) destacam que estudos anteriores analisaram esta relação sob a perspectiva dos indicadores financeiros de forma individualizada, o que pode causar vieses de interpretação de resultados, principalmente no que tange à mensuração do desempenho das organizações.

Este estudo distingue-se dos demais sob diversos aspectos. Inicialmente, este estudo se utilizoude um método diferenciado na mensuração do desempenho econômico e financeiro das organizações $\left(\mathrm{DP}_{2}\right)$, quea partir da conjunção de diversas variáveis, é possível transformálas em um único indicador de desempenho. Em relação à remuneração dos executivos, estudos tem classificado como remuneração fixa e variável, enquanto este estudo desdobra a remuneração variável em curto e longo prazo. Por fim, enquanto a maioria das pesquisas têmse utilizado de regressões lineares, a presente pesquisa inova trazendo para o contexto da remuneração dos executivos a regressão quadrática. Com a utilização de tal abordagem, espera-se fornecer novos insigths teóricos e empíricos acerca da relação entre remuneração executiva e desempenho econômico e financeiro das organizações. Como contribuição prática, ajude as organizações na elaboração de pacotes de remuneração que incentive os gestores na busca do alcance das metas pré-estabelecidas, alinhando os interesses do gestores com os dos acionistas e, melhorar a performance econômica e financeira das organizações.

\section{REFERENCIAL TEÓRICO}

\subsection{Remuneração dos Executivos}

A literatura acerca da remuneração dos executivos data da década de 1970 juntamente com a evolução da Teoria da Agência (Jensen e Meckling, 1976), indicando a separação entre propriedade e controle das empresas. Nesta separação de propriedade e controle, gestores (agente) podem usar recursos corporativos para maximizar seus interesses que não estejam alinhados com os interesses dos acionistas (principal).Bradley (2013) indica que uma maneira de mitigar este conflito de interesses entre agente e principal encontra-se os contratos de compensação. A esse respeitoFarmer, Alexandrou e Archbold (2010) mencionam que os contratos incluemo desenvolvimento de um sistema de monitoramento do comportamento e 
Leite e Hein (2019)

Relação entre Remuneração dos Executivo e o Desempenho

Econômico e Financeiro em Empresas Brasileiras

decisões do gestor para garantir que estes não se desviem dos interesses dos acionistas, ou então, pelo estabelecimento de incentivos que recompensem o agente por resultados.

Silva e Chien (2013) destacam que a vinculação da remuneração dos executivos ao desempenho da organização não é capaz de observar o comportamento do gestor como um todo, sendo assim, contratos que estabeleçam uma relação entre a remuneração e o resultado da organização consiste em um importante instrumento de monitoramento das ações dos gestores.Embora haja uma diversidade de pacotes de remuneração, a maioria deles contêm quatro conjuntos principais, sendo eles o salário base, o bônus anual ligado ao desempenho contábil, opções de ações e planos de incentivos de longo prazo. Além disso um conjunto de planos de benefícios aos empregados e benefícios específicos são contemplados, como seguros de vida e planos de aposentadoria.

Murphy (1999) pontua que os executivos tendem a preferir salário fixo, apesar deste representar uma pequena parcela da remuneração total, especialmente pela aversão ao risco bem como pelo fato de outras formas de remuneração serem, geralmente, baseados em percentuais do salário fixo.Sob tal perspectiva, Ermel e Monte (2016, p. 7-8) entendem que que a remuneração fixa atenua o conflito de agência, no entanto "devido ao fato de que o gestor pode não se sentir motivado a exercer a sua função e obter o máximo de valor, sendo considerada a remuneração fixa uma posição de conforto".Nascimento et al. (2013, p. 2) destacam que "o estabelecimento de uma remuneração variável atrelada ao desempenho da empresa consistenuma tentativa dos proprietários em sincronizar interesses". Dessa forma, a remuneração variável incentivao gestor a maximizar o resultado da empresaà medida remuneração dependa, em medida, do desempenho da empresa (ERMEL; MONTE, 2016).

Conforme Silva e Chien (2013, p. 482), "nada mais benéfico para os acionistas e os executivos que o correto desenho de um pacote remuneratório atrativo e compatível com a realidade de mercado, que apresente incentivos de curto e longo prazo com metas claras de desempenho que os administradores da empresa devem perseguir".O Quadro 1 apresenta uma síntese dos principais itens da remuneração dos executivos.

Quadro 1 - Síntese da remuneração dos executivos

\begin{tabular}{|c|c|c|}
\hline Remuneração Fixa & $\begin{array}{l}\text { Remuneração Variável de Curto } \\
\text { Prazo }\end{array}$ & $\begin{array}{l}\text { Remuneração Variável de Longo } \\
\text { Prazo }\end{array}$ \\
\hline \begin{tabular}{l}
\multicolumn{1}{c}{ Diretos: } \\
Salário base \\
Contribuições sociais \\
Gratificações anuais \\
Décimo terceiro salário \\
Férias
\end{tabular} & $\begin{array}{l}\text { Gain Sharing: remunera em função } \\
\text { da redução de custos ou aumento da } \\
\text { produtividade }\end{array}$ & $\begin{array}{l}\text { Stock Options: incentivos que } \\
\text { possibilitam aos empregados a } \\
\begin{array}{l}\text { aquisição de ações com preço } \\
\text { subsidiado }\end{array}\end{array}$ \\
\hline $\begin{array}{l}\quad \text { Indiretos: } \\
\text { Assistência médica } \\
\text { Aluguéis } \\
\text { Auxílio alimentação } \\
\text { Carro } \\
\text { Entre outros }\end{array}$ & $\begin{array}{l}\text { Profit Sharing: são os lucros } \\
\text { distribuídos em um determinado } \\
\text { período }\end{array}$ & $\begin{array}{l}\text { Benefícios de remuneração em ações: } \\
\text { proporciona pagamento futuro } \\
\text { vinculado ao valor de mercado das } \\
\text { ações da entidade }\end{array}$ \\
\hline $\begin{array}{l}\text { Skill-Based-Pay:remuneração } \\
\text { com base nas habilidades ou } \\
\text { conhecimentos (podem ser } \\
\text { apresentados também como } \\
\text { remuneração de longo prazo) }\end{array}$ & $\begin{array}{l}\text { Pay-for-Performance: vincula-se ao } \\
\text { alcance de metas/resultados } \\
\text { individuais, traduzindo-se em bônus } \\
\text { ou gratificações em dinheiro, } \\
\text { geralmente recebidos no final do } \\
\text { exercício social }\end{array}$ & $\begin{array}{l}\text { Pós-emprego: acordos formais } \\
\text { informais que comprometem a } \\
\text { entidade com o empregado após a } \\
\text { extinção do vínculo de serviço, como } \\
\text { por exemplo plano de aposentadoria } \\
\text { complementar, pensões, seguros de } \\
\text { vida }\end{array}$ \\
\hline
\end{tabular}

Fonte: adaptado de Oliva \& Albuquerque (2007). 
Leite e Hein (2019)

Relação entre Remuneração dos Executivo e o Desempenho

Econômico e Financeiro em Empresas Brasileiras

A utilização de números contábeis e financeiros na determinação da bonificação dos executivos tem a vantagem de ser uma metodologia clara e objetiva. Esta metodologia pode trazer problemas como a manipulação contábil, deixando projetos de longo prazo em segundo plano. Por outro lado, metas de curto prazo pode desmotivar os executivos quando estas metas forem atingidas ou quando forem difíceis de serem alcançadas. Sendo assim, é essencial a existência de diferentes formas de remuneração e incentivos para um eficiente modelo de remuneração executiva (MURPHU, 1999).

Farmer et al. (2010) explicam quepagamentos de incentivos de curto prazo são normalmentevinculados a uma medida de rentabilidade contábil, enquanto os incentivos a longo prazo estão sujeitos ao desempenho das empresas por meio de métricas como crescimento do lucro por ação, retorno total do acionista, para citar alguns deles. A despeito disso, Bradley (2013) destaca que, para maximizar o desempenho dos executivos, e limitar o conflito de interesses, as organizações devem acordar métodos para a mensuração de desempenho adequados, havendo dessa forma, um link claro e compreensível entre o desempenho da empresa e o sistema de remuneração. Todas as contingências deste modelo de remuneração deve sercomunicada à todas as partes envolvidas. A compreensão clara do que constitui um bom desempenho também precisa ser acordada.

O papel do poder gerencial na formação do pacote de compensação executiva podem produzir distorções consideráveis nesses arranjos, resultado em custos para os investidores, pois enfraquecem os incentivos dos gestores para aumentar o valor da empresa ou até mesmo reduzi-lo.A esse respeito, Gong (2011) explica que pelo fato de gestores terem, geralmente, horizontes temporais mais curtos em relação aos acionistas, preferem investir em projetos de curto prazo, buscam assim produzir retornos mais rápidos, o que gera uma maior percepção de sua capacidade gerencial e, quando os gestores se desviam das metas de longo prazo, podem deixar de criar valor paras seus acionistas.

As discussões acerca da remuneração dos executivos evoluíram de forma interdisciplinar, e embora haja heterogeneidade nas práticas de remuneração dos executivos entre as empresas (Machado; Beuren, 2015), o efeito da remuneração sobre o desempenho das organizações é ainda uma questão em aberto (Edmans et al.2017), uma vez que resultados de estudos anteriores são ambíguos (SILVA; CHIEN, 2013; SOUZA et al., 2017).Aguiar e Pimentel (2017) sublinham que não se tem ao certo se o nível de remuneração de fato é capaz de motivar os executivos a buscar desempenho superior no contexto brasileiro.

\subsection{Relação da Remuneração dos Executivos e o Desempenho Econômico e Financeiro}

A remuneração executiva é uma questão controversa, atraindo atenção de pesquisadores, investidores, legisladores e a mídia em geral. Enquanto a mídia e os políticostendem a concentrar a atenção na escala de remuneração dosexecutivos, acadêmicos, investidores e legisladores preocupam-se em saber se a remuneração dos executivos está vinculada ao desempenho corporativo (FARMER et al., 2010).Pressupõe-se que os modelos de remuneração executiva, e de outros incentivos podem melhorar o desempenho das organizações.Assim, inúmeros estudos objetivaram analisar as interrelações entre os sistemas de remuneração e o desempenho das organizações.

Conforme Silva e Chien (2013), a maioria dos estudos sugerem que empresas que remuneram melhor seus executivos apresentam desempenho superior em relação àquelas que remuneram em menor volume, no entanto, estas evidências no Brasil não são significativas. Os autores acreditam que uma das possíveis explicações "é que as firmas que melhor remuneram seu alto escalão atrairão os profissionais mais bem preparados e com maior 
Relação entre Remuneração dos Executivo e o Desempenho Econômico e Financeiro em Empresas Brasileiras

experiência, possibilitando desempenho superior ao dos concorrentes", além de contribuir para a elevação do valor da organização (SILVA; CHIEN, 2013, p. 483).

$\mathrm{O}$ uso de medidas de compensação com base em desempenho é uma condição necessária para investigar a relação entre o desempenho corporativo e a remuneração do principal executivo da empresa. A despeito disso, Farmer et al. (2010) fazem lembrar que os planos de remuneração por desempenho não podem estar desassociados do desempenho dos demais executivos da organização.Dada tais perspectivas, apresenta-se resultados de estudos que vincularam a remuneração dos executivos com o desempenho das organizações, levandose em consideração métricas contábeis de desempenho bem como métricas de mercado.

Souza et al. (2017) verificaram a relação da remuneração dos executivos com o desempenho financeiro de empresas brasileiras. Os resultados não apresentaram relação significativa entre remuneração e desempenho financeiro baseado apenas em indicadores financeiros, encontrando apenas relação positiva e significativa quando considerados indicadores financeiros e não financeiros e em conjunto. Ademias, os resultados também não encontraram relação com o desempenho de mercado. Para os autores, os resultados evidenciam que planos de incentivos que se baseiam em indicadores financeiros e ausência de relação entre desempenho de mercado, não alinham os interesses dos gestores aos dos acionistas.

Aguiar e Pimentel (2017)analisaram a relação entre a remuneração dos executivos e o desempenho das empresas também levando-se em consideração a composição da remuneração no desempenho financeiro e de mercado nos níveis contemporâneos e defasados. Os resultados demonstraram que as empresas que pagam maiores níveis de remuneração aos seus executivosobtémmaiores níveis de desempenho, tanto de curto quanto de longo prazo.

Konraht et al. (2018) investigaram a relação da remuneração variável no desempenho organizacionalutilizando-se de métricas de rentabilidade, volume de vendas e geração de caixa. Os resultados indicaram que um maior percentual de remuneração variável não gera necessariamente um aumento do desempenho da organização. Este resultado corrobora com o estudo de Bradley (2013) no contexto sul africano. Estes resultados sugerem o não alinhamento dos interesses entre gestores e acionistas, implicando em baixo desempenho das organizações.

Referente as relações existentes entre os pacotes de remuneração dos executivos e desempenho das organizações, Oberholzer e Barnard (2015) indicam que há uma variedade de medidas de desempenho, mensurados por indicadores contábeis e de mercado, empregadas nos mais diversos estudos. A maioria destes estudos se utilizam de métricas contábeis e de mercado de forma separada e individualizada, o que possivelmente pode acarretar em viés de análise (Konraht et al., 2018) e que, para Oberholzer e Barnard (2015), consiste em uma importante falha de pesquisa, contribuindo assim para resultados mistos (NASCIMENTO et al., 2013; SILVA; CHIEN, 2013; SOUZA et al., 2017).

De forma geral, se verificaque a relação entre a remuneração dos executivos e o desempenho das organizações tem sido foco de diversos estudos, cujos resultados apresentam-se divergentes. A partir destas considerações que se estimula a realização do presente estudo, que pretende analisar a relação entre a remuneração dos executivos e o desempenho econômico e financeiro em empresas brasileiras. Sendo assim, este estudo diferencia-se dos demais por se utilizar de uma métrica única de mensuração do desempenho econômico e financeiro que contemple tanto indicadores econômicos como de mercado.

\section{PROCEDIMENTOS METODOLÓGICOS}


Leite e Hein (2019)

Relação entre Remuneração dos Executivo e o Desempenho Econômico e Financeiro em Empresas Brasileiras

Este estudo tem por objetivo analisar a relação entre a remuneração dos executivos e o desempenho econômico e financeiro em empresas brasileiras. Realizou-se pesquisa descritiva, de abordagem quantitativa, e de análise documental. A população compreendeu as empresas listadas na BM\&FBovespa. A amostra se constituiu nas 50 companhias listadas no IBrX50. Optou-se por esta amostra em função de apresentarem maior volume de negociações no mercado de ações brasileiro (BM\&FBOVESPA, 2018). Da referida amostra, foram excluídas as organizações do seguimento financeiro por possuírem características específicas do setor, bem como aquelas que não possuíam informações suficientes para a operacionalização de todas as variáveis em estudo. Desta forma, ao todo a amostra da pesquisa abrangeu 36 empresas, sendo o período de análise entre os anos de 2012 a 2017, totalizando 216 observações.

Os dados referente à remuneração dos executivos foram coletados no formulário de referência das empresas analisadas, disponibilizadas no website da BM\&FBovespa. Já os dados relacionados ao desempenho econômico e financeiro das empresas foram coletados na base de dados Economática ${ }^{\circledR}$. A descrição das variáveis são apresentadas no Quadro 2.

Quadro 2 - Constructo das Variáveis de Pesquisa

\begin{tabular}{|c|c|c|}
\hline Variável & Fórmula & Fonte \\
\hline \multicolumn{3}{|c|}{ Variáveis de Remuneração } \\
\hline \multirow{2}{*}{ Remuneração Fixa (RFX) } & Remuneração Fixa & \multirow{7}{*}{$\begin{array}{l}\text { Formulário de } \\
\text { Referência }\end{array}$} \\
\hline & $\overline{\text { Remuneração Total }}$ & \\
\hline Remuneracão Variável de Curto Prazo & Remuneração Variável & \\
\hline (RVCP) & de Curto Prazo & \\
\hline \multirow{2}{*}{$\begin{array}{c}\text { Remuneração Variável de Longo Prazo } \\
\text { (RVLP) }\end{array}$} & $\begin{array}{c}\text { Remuneração Variável } \\
\text { de Longo Prazo }\end{array}$ & \\
\hline & $\overline{\text { Remuneração Total }}$ & \\
\hline Remuneração Total (RMT) & Log Remuneração Total & \\
\hline \multicolumn{3}{|c|}{ Variáveis de Desempenho Econômico e Financeiro } \\
\hline \multirow{2}{*}{ Retorno sobre os Ativos (ROA) } & EBIT & \multirow{12}{*}{ Economática $^{\circledR}$} \\
\hline & $\overline{\text { Ativo Total }}$ & \\
\hline \multirow{2}{*}{$\begin{array}{l}\text { Retorno sobre o Patrimônio Líquido } \\
\text { (ROE) }\end{array}$} & Lucro Líquido & \\
\hline & $\overline{\text { Patrimônio Líquido }}$ & \\
\hline \multirow{2}{*}{ Retorno sobre as Vendas (ROS) } & Lucro Líquido & \\
\hline & $\overline{\text { Receita Operacional Líquida }}$ & \\
\hline \multirow[t]{2}{*}{ Q de Tobin (QTB) } & $\begin{array}{c}\text { Valor de Mercado + Passivo Circulante - } \\
\text { Ativo Circulante + Estoques + Dívidas } \\
\text { de Longo Prazo }\end{array}$ & \\
\hline & $\begin{array}{c}\text { Ativo Total } \\
\end{array}$ & \\
\hline \multirow{2}{*}{ Market to Book Value (MTB) } & Valor de Mercado & \\
\hline & $\overline{\text { Patrimônio Líquido }}$ & \\
\hline \multirow{2}{*}{ Lucro por Ação (LPA) } & Lucro Líquido & \\
\hline & $\overline{\text { Quantidade de Ações }}$ & \\
\hline
\end{tabular}

Fonte: dados da empresa (2019).

Considerou-se como remuneração dos executivos a remuneração da Diretoria Estatutária, que são compostas por a) Remuneração Fixa (salários e pró-labore, benefícios diretos e indiretos, participação em comitês, outros valores fixos); b) Remuneração Variável de Curto Prazo (bônus, participação de resultados, participação em reuniões, comissões, outros valores variáveis); c) Remuneração Variável de Longo Prazo (pós-emprego, cessão do cargo, baseado em ações) e; d) Remuneração Total (log da soma de todas as remunerações pagas). 
Leite e Hein (2019)

Relação entre Remuneração dos Executivo e o Desempenho

Econômico e Financeiro em Empresas Brasileiras

Para estabelecer o desempenho econômico e financeiro se utilizoudos seguintes indicadores: a) Rentabilidade (Retorno sobre os Ativos, Retorno sobre o Patrimônio Líquido e Retorno sobre as Vendas) e; b) Desempenho de Mercado (Q de Tobin, Market to Book Value e o Lucro por Ação).

Para análise dos resultados aplicou-se inicialmente estatística descritiva a fim de apresentar e sumarizar o conjunto de variáveis utilizadas no estudo. Para criar o indicador de desempenho único, considerando as variáveis de desempenho econômico e financeiro, utilizou-se a técnica $\mathrm{DP}_{2}$. Esta técnica foi elaborada por Trapero (1977), cria um indicador sintético que tem por finalidade a comparação interespacial e/ou intertemporal de variáveis.

As vantagens deste método consistem na atribuição de pontuação a cada elemento (empresa) envolvido na análise, formando um ranking dos elementos envolvidos frente ao que a realidade permitetrabalhar com pontos de referência hierarquicamente construídos, além de possibilitar a mensuração de disparidades entre os envolvidos.Para isso, o método necessita de uma matriz, cujas empresas são apresentadas nas linhas e as variáveis nas colunas. Cada elemento $x_{i j}$ da matriz representa o valor associado da empresa i na variável $\mathrm{j}$.

O indicador sintético é construído segundo cada hipótese inerente ao método: completitude e linearidade. Especificamente, (i) completitude: o número das componentes é tal que todas as propriedades relacionadas com o objeto buscado pelo indicador global representadas por meio de suas componentes (variáveis); (ii) linearidade: a relação existente entre os distintos componentes é linear, ou seja, $x_{j}=\alpha_{0}+\alpha_{1} x_{1}+\cdots+\alpha_{j-1} x_{j-1}+\varepsilon_{j-1}$; para $\mathrm{j}=1, \ldots, \mathrm{n}$. Com essa suposição define-se a distância $\mathrm{DP}_{2}$ conforme apresentada na Equação 1:

$D P_{2}=\sum_{j=1}^{n} \frac{d_{j}}{\sigma_{j}}\left(1-R_{j, j-1, j-2, \ldots, 1}^{2}\right), \operatorname{com} R_{1}^{2}=0$

Onde:

$d_{j}=d_{j}(r, k)=\left|x_{r j}^{*}-x_{i j}\right|$, em que r é base de referência;

$\frac{d_{j}}{\sigma_{j}}$ é o indicador parcial da componente $\mathrm{j}$ (variável).

Conforme Zarzosa (1996), ao dividir a distância d $\mathrm{j}_{\mathrm{j}}$ pelo desvio-padrão da componente, o indicador perde as unidades nas quais foi mensurado. Esse procedimento soluciona $o$ problema de heterogeneidade das unidades de medida dos indicadores parciais, por outro lado, serve como sistema de ponderação mediante o qual se consegue dar menor importância as distâncias correspondentes as componentes, cujos valores apresentem maior dispersão em relação à média. $\mathrm{O}$ fator $\left(1-R_{j, j-1, j-2, \ldots, 1}^{2}\right)$ evita a duplicidade de informaçãoeliminando indicadores parciais da informação já contida em outros indicadores precedentes.

Contudo há uma discussão anterior a aplicação do método $\mathrm{DP}_{2}$, pois seus resultados variam dependendo da ordem de entrada das componentes (variáveis). Neste sentido é imperativo fixar uma hierarquia de entrada de variáveis. O critério lógico de ordenação é o de atender a quantidade de informação sobre o objeto a mensurar e que cada indicador aporta ao indicador sintético.A hierarquia assumida neste estudo foi de verificar a distância de Frechet, que é o máximo valor que a distância $\mathrm{DP}_{2}$ pode assumir e que é definida como a soma dos indicadores parciais, assim apresentada na Equação 2:

$F_{j}=\sum_{j=1}^{n} \frac{d_{j}}{\sigma_{j}}$

Em linhas gerais pode-se formular o algoritmo para o cálculo do $\mathrm{DP}_{2}$ dos indicadores econômicos e financeiros das empresas analisadas pela presente pesquisa: 
a) estabelecimento da matriz de valores das componentes das m empresas envolvidas;

b) verificar os critérios das $n$ variáveis envolvidas quanto a sua conduta, ou seja, classificar as variáveis quanto a seu objetivo: "quanto maior, melhor" ou "quanto menor, melhor";

c) eleição da base de referência em cada variável, determinando seu ideal teórico; calcular as distâncias de Frechet;

d) ordenação das componentes de maior para menor à hierarquização do modelo;

e) obtenção do $\mathrm{DP}_{2}$ de cada empresa fazendo entrar as componentes segundo a hierarquia definida em (e) e;

f) iterações consecutivas até que todas as variáveis tenham sido incorporadas ao modelo.

Cabe destacar que quanto maior a distância $\mathrm{DP}_{2}$ de um elemento, mais longe ele estará do valor teórico de referência. Assim, quanto maior o valor do $\mathrm{DP}_{2}$ (empresa) mais bem posicionada ela estará em caso da formação de um ranking.Para esta pesquisa, é necessário inverter a posição do DP2 para quanto maior mais perto do valor teórico de referência, uma vez que se deseja relacionar maior remuneração com maior desempenho.

Por fim, para analisar a relação entre a remuneração dos executivos e o desempenho econômico e financeiro das empresas a partir da técnica do $\mathrm{DP}_{2}$, foram elaborados os seguintes modelos de regressão:

$$
\begin{aligned}
& D P 2=\beta_{0}+\beta_{1} R F X_{i t}+\varepsilon_{i t} \\
& D P 2=\beta_{0}+\beta_{1} R F X_{i t}+\beta_{2} R F X^{2}{ }_{i t}+\varepsilon_{i t} \\
& D P 2=\beta_{0}+\beta_{1} R V C P_{i t}+\varepsilon_{i t} \\
& D P 2=\beta_{0}+\beta_{1} R V C P_{i t}+\beta_{2} R V C P^{2}{ }_{i t}+\varepsilon_{i t} \\
& D P 2=\beta_{0}+\beta_{1} R V L P_{i t}+\varepsilon_{i t} \\
& D P 2=\beta_{0}+\beta_{1} R V L P_{i t}+\beta_{2} R V L P^{2}{ }_{i t}+\varepsilon_{i t} \\
& D P 2=\beta_{0}+\beta_{1} R M T_{i t}+\varepsilon_{i t} \\
& D P 2=\beta_{0}+\beta_{1} R M T_{i t}+\beta_{2} R M T^{2}{ }_{i t}+\varepsilon_{i t}
\end{aligned}
$$

Os modelos 1, 3, 5 e 7 são constituídos por regressões lineares, similarmente a maioria dos estudos acerca do tema observados na literatura, enquanto os modelos 2, 4, 6 e 8 visam, por intermédio do termo quadrático, observar a relação entre a remuneração dos executivos e o desempenho econômico e financeiros das empresas. Tanto para a análise descritiva dos dados quanto para a análise dos modelos de regressão utilizou-se o software SPSS ${ }^{\circledR}$.

\section{ANÁLISE E DISCUSSÃO DOS RESULTADOS}

Os dados apresentados na Tabela 1 se referemà estatística descritiva das variáveis de desempenho econômico e financeiro das empresas que compõem a amostra do estudo.

Tabela 1 - Estatística descritiva das variáveis de desempenho econômico e financeiro

\begin{tabular}{c|ccccc|ccccc}
\hline Ano & Var. & Min. & Máx. & Méd. & D. Pad. & Var. & Min. & Máx. & Méd. & D. Pad. \\
\hline 2012 & & $-0,0462$ & 0,2559 & 0,0808 & 0,0653 & & $-0,1025$ & 0,6594 & 0,1245 & 0,1620 \\
2013 & & $-0,0375$ & 0,2266 & 0,0889 & 0,0558 & & $-0,1039$ & 0,7355 & 0,1255 & 0,1547 \\
2014 & ROA & $-0,0276$ & 0,2196 & 0,0883 & 0,0519 & ROE & $-0,0699$ & 0,6521 & 0,1302 & 0,1380 \\
2015 & & $-0,1307$ & 0,2083 & 0,0744 & 0,0721 & & $-0,3431$ & 1,5526 & 0,1100 & 0,3063 \\
2016 & & $-0,0300$ & 0,2040 & 0,0815 & 0,0527 & & $-0,1509$ & 0,4390 & 0,1076 & 0,1325
\end{tabular}


Leite e Hein (2019)

Relação entre Remuneração dos Executivo e o Desempenho

Econômico e Financeiro em Empresas Brasileiras

\begin{tabular}{|c|c|c|c|c|c|c|c|c|c|c|}
\hline 2017 & & $-0,0509$ & 0,1891 & 0,0832 & 0,0499 & & $-0,1005$ & 0,6264 & 0,1188 & 0,1305 \\
\hline Per. & & $-0,1307$ & 0,2559 & 0,0829 & 0,0580 & & $-0,3431$ & 1,5526 & 0,1194 & 0,1795 \\
\hline 2012 & & $-0,1740$ & 1,5504 & 0,1248 & 0,2765 & & 0,4126 & 5,0729 & 1,5025 & 1,1133 \\
\hline 2013 & & $-0,2230$ & 0,6167 & 0,0947 & 0,1578 & & 0,3511 & 4,0472 & 1,3641 & 0,8343 \\
\hline 2014 & & $-0,1002$ & 0,6049 & 0,1024 & 0,1369 & & 0,4602 & 3,6876 & 1,2461 & 0,6981 \\
\hline 2015 & ROS & $-0,5171$ & 0,5896 & 0,0410 & 0,1990 & QTB & 0,4103 & 3,2807 & 1,0982 & 0,6144 \\
\hline 2016 & & $-0,0792$ & 0,6197 & 0,1147 & 0,1478 & & 0,4460 & 3,8183 & 1,2377 & 0,7085 \\
\hline 2017 & & $-0,6294$ & 0,6019 & 0,0885 & 0,1751 & & 0,5688 & 4,9613 & 1,4625 & 0,9894 \\
\hline Per. & & $-0,6294$ & 1,5504 & 0,0943 & 0,1878 & & 0,3511 & 5,0729 & 1,3185 & 0,8465 \\
\hline 2012 & & 0,1441 & 21,1790 & 3,6252 & 4,7013 & & $-5,0856$ & 8,3915 & 1,2854 & 2,1618 \\
\hline 2013 & & 0,1491 & 15,4927 & 3,0176 & 3,2455 & & $-4,6477$ & 3,9834 & 0,9400 & 1,4690 \\
\hline 2014 & & 0,1499 & 12,1604 & 2,6836 & 2,7570 & & $-2,2409$ & 4,7915 & 1,1454 & 1,4241 \\
\hline 2015 & МТВ & 0,2068 & 11,3254 & 2,5752 & 2,7389 & LPA & $-10,6767$ & 4,0712 & 0,2386 & 2,9793 \\
\hline 2016 & & 0,5876 & 10,9692 & 2,9706 & 2,7799 & & $-1,8131$ & 4,3117 & 1,1378 & 1,4963 \\
\hline 2017 & & 0,5899 & 9,3925 & 3,0796 & 2,4711 & & $-1,3876$ & 5,1292 & 1,3427 & 1,5246 \\
\hline Per. & & 0,1441 & 21,1790 & 2,9920 & 3,1839 & & $-10,6767$ & 8,3915 & 1,0150 & 1,9410 \\
\hline
\end{tabular}

Legenda:Var. = variáveis; ROA = Retorno sobre os Ativos; ROE $=$ Retorno sobre o Patrimônio Líquido; ROS = Retorno sobre as Vendas; QTB = Q de Tobin; MTB = Market to Book Value LPA = Lucro por Ação; Min.

Fonte: dados da pesquisa (2019).

Conforme Tabela 1, a rentabilidade média sobre os ativos (ROA)foi de 8,29\%,a rentabilidade sobre o patrimônio líquido (ROE) foi de $11,94 \%$ e, a rentabilidade sobre as vendas (ROS) foi de 9,43\%. Os índices de retorno apresentaram constância em seus valoresquando analisado anualmente, ratificado pelo baixo valor do desvio padrão. Com estes dados, pode-se inferir que, em média, as empresas analisadas apresentaram rentabilidade positiva no período analisado. Em relação aos indicadores de desempenho financeiro, se observar que o Q de Tobin (QTB) apresentou em médiade 1,3185. Como o valor foi maior do que 1 , isto indica que o valor das organizações é superior à reposição dos seus ativos (GUIMARÃES; PEIXOTO, 2015). Isto indica que as empresas estão sendo eficiente na alocação dos seus investimentos, e com isso criando valor para as empresas.

O Market to Book Value (MTB) apresentou média de 2, 9920, revelando que as empresas possuem valor quase 3 vezes superior ao seu valor contábil.Por fim, a lucratividade por ação (LPA) apresentou valor de $15 \%$.Diferentemente dos indicadores de desempenho econômico, os indicadores de desempenho financeiro não obtiveram constância no período analisado, observado pelo alto valor do desvio padrão. Pode-se inferirque, os retornos do ponto de vista econômico são mais constantes em relação ao desempenho de mercado. A Tabela 2 apresenta a estatística descritiva da remuneração dos executivos.

Tabela 2 - Estatística descritiva da remuneração dos executivos

\begin{tabular}{|c|c|c|c|c|c|c|c|c|c|c|}
\hline Ano & Var. & Min. & Máx. & Méd. & D. Pad. & Var. & Min. & Máx. & Méd. & D. Pad. \\
\hline 2012 & \multirow{7}{*}{ RFX } & 0,0552 & 1,0000 & 0,4604 & 0,2267 & \multirow{7}{*}{ RVCP } & 0,0000 & 0,7685 & 0,3736 & 0,1981 \\
\hline 2013 & & 0,0595 & 1,0000 & 0,4783 & 0,2101 & & 0,0000 & 0,8383 & 0,3675 & 0,1762 \\
\hline 2014 & & 0,0840 & 1,0000 & 0,4630 & 0,2307 & & 0,0000 & 0,6720 & 0,3453 & 0,1769 \\
\hline 2015 & & 0,0786 & 0,9517 & 0,4346 & 0,2298 & & 0,0000 & 0,6499 & 0,3248 & 0,1649 \\
\hline 2016 & & 0,1325 & 0,8919 & 0,4014 & 0,2120 & & 0,0000 & 0,7445 & 0,3353 & 0,1866 \\
\hline 2017 & & 0,1027 & 0,8499 & 0,4033 & 0,1912 & & 0,0000 & 0,6756 & 0,3402 & 0,1784 \\
\hline Per. & & 0,0552 & 1,0000 & 0,4402 & 0,2167 & & 0,0000 & 0,8383 & 0,3478 & 0,1792 \\
\hline 2012 & \multirow{7}{*}{ RVLP } & 0,0000 & 0,6504 & 0,1661 & 0,1859 & \multirow{7}{*}{ RMT } & 12,2706 & 18,4383 & 16,5555 & 1,1348 \\
\hline 2013 & & 0,0000 & 0,5039 & 0,1542 & 0,1441 & & 12,4708 & 18,1040 & 16,6708 & 1,0180 \\
\hline 2014 & & 0,0000 & 0,7416 & 0,1917 & 0,1874 & & 12,7509 & 18,3616 & 16,9322 & 1,0591 \\
\hline 2015 & & 0,0000 & 0,7503 & 0,2406 & 0,1945 & & 13,2547 & 18,4697 & 17,0679 & 1,0348 \\
\hline 2016 & & 0,0000 & 0,7487 & 0,2633 & 0,1796 & & 14,2462 & 18,3843 & 17,1309 & 0,9179 \\
\hline 2017 & & 0,0000 & 0,7529 & 0,2565 & 0,1833 & & 13,5795 & 18,8088 & 17,1247 & 1,0166 \\
\hline Per. & & 0,0000 & 0,7529 & 0,2121 & 0,1830 & & 12,2706 & 18,8088 & 16,9137 & 1,0447 \\
\hline
\end{tabular}


Leite e Hein (2019)

Relação entre Remuneração dos Executivo e o Desempenho

Econômico e Financeiro em Empresas Brasileiras

Legenda:RFX = Remuneração Fixa; RVCP = Remuneração Variável de Curto Prazo; RVLP = Remuneração Variável de Longo Prazo; RMT = Remuneração Total.

Fonte: dados da pesquisa (2019).

Conforme a Tabela 2, a remuneração fixa (RFX) foi de 44,02\%da remuneração total.Se verifica queno ano de 2012, este percentual foi de $46,04 \%$, enquanto em 2017 , caiu para 44,02\%, ou seja, queda de 2,02 pontos percentuais.Enquanto isso, a remuneração variável de curto prazo (RVCP) foi de $34,78 \%$ da remuneração total. Seguindo a mesma tendência da remuneração fixa (RFX), houve uma queda de 2,58 pontos percentuais em 2017 comparativamente ao ano de 2012, início do período analisado.

Em relação à remuneração variável de longo prazo (RVLP), a média foi de $21,21 \%$ da remuneração total. No sentido inverso do observado na remuneração fixa (RFX) e na remuneração variável de curto prazo (RVCP), houve um aumento de 4,60 pontos percentuais, passando de 16,61\% em 2012 para 21,21\% em 2017.Estas três formas de remuneração apresentaram baixa amplitude, indicando baixa variação entre as remunerações mínimas e máximas, corroboradas pelo baixo desvio padrão. Assim, as remuneraçõestendem a se estabelecer próximo da média.

Com base nesses resultados, percebe-se que a remuneração variável de curto prazo e a remuneração de longo prazo, têm se tornado importantes componentes da estrutura da remuneração total dos seus executivos, pois estas duas remunerações, quando somadas, representam em média quase $60 \%$ da remuneração total.Isto contraria as expectativas dos executivos que tentem a preferir salários fixos em virtude da aversão ao risco e pelo fato de que este tipo de remuneração vincula outras formas de remunerações variáveis (MURPHY, 1999).

Por fím, em relação à remuneração total (RMT) dos executivos, se observa a manutenção de sua ascendência em todo o período analisado, com exceçãodo ano de 2017 que caiu em relação ao ano anterior, no entanto, ainda superior ao observado nos anos de 2012 e 2013. Cabe destacar que, em função do desvio padrão ser alto, e pela amplitude entre os valores mínimos e máximos, há uma alta dispersão dos valores totais pagos aos executivos.Este resultado é similar aos resultados encontrados pelos estudos de Machado e Beuren (2015), o que sugere que as empresas se preocupam com a remuneração total de seu corpo executivo.Esta ascendência pode ter sido influenciada pela intensificação da remuneração variável em detrimento da redução da remuneração fixa.

Após apresentar as estatísticas descritivas das variáveis de desempenho econômico e financeiro das organizaçõese das remunerações dos executivos, se apresenta na Tabela 3 os resultados obtidos mediante a aplicação da distância $\mathrm{DP}_{2}$ conforme descrito nos procedimentos metodológicos, que fornece um ranking de desempenho econômico e financeiro das empresas que compõem a amostra do estudo. Neste sentido, as empresas que evidenciaram maior valor de $\mathrm{DP}_{2}$ em cada ano se posicionam na primeira posição do ranking. Somando o $\mathrm{DP}_{2}$ de todos os anos, se estabelece a posição do ranking geral.

Tabela 3 - Ranking $\mathrm{DP}_{2}$

\begin{tabular}{|c|c|c|c|c|c|c|c|c|}
\hline Pos. & Empresa & $\mathrm{DP}_{2} 2012$ & $\mathrm{DP}_{2} 2013$ & $\mathrm{DP}_{2} 2014$ & $\mathrm{DP}_{2} 2015$ & $\mathrm{DP}_{2} 2016$ & $\mathrm{DP}_{2} 2017$ & $\mathrm{DP}_{2}$ Geral \\
\hline $1^{\circ}$ & Ambev & 11,2030 & 13,6921 & 12,7661 & 13,4963 & 13,9330 & 11,8490 & 76,9395 \\
\hline $2^{\circ}$ & Natura & 11,8570 & 16,4601 & 13,6990 & 11,3645 & 10,5202 & 11,0344 & 74,9352 \\
\hline $3^{\circ}$ & CCR & 9,3480 & 14,0178 & 11,7894 & 10,2627 & 12,0052 & 9,7610 & 67,1841 \\
\hline $4^{a}$ & Lojas Renner & 8,7980 & 13,0421 & 11,5580 & 10,6508 & 11,1277 & 11,5429 & 66,7196 \\
\hline $5^{\circ}$ & Taesa & 8,2075 & 13,2939 & 11,3105 & 10,1537 & 11,7623 & 10,6358 & 65,3637 \\
\hline $6^{\circ}$ & Raia Drogasil & 6,6522 & 9,8426 & 8,7888 & 11,0185 & 12,7438 & 12,3994 & 61,4454 \\
\hline $7^{\circ}$ & Multiplan & 8,6900 & 11,7985 & 10,4331 & 9,4771 & 10,0594 & 9,6912 & 60,1492 \\
\hline $8^{\circ}$ & Lojas Americanas & 9,3179 & 12,4866 & 10,8199 & 10,0169 & 9,3825 & 7,0650 & 59,0889 \\
\hline $9^{\circ}$ & Ultrapar & 7,3592 & 11,9719 & 9,5349 & 10,1106 & 9,9464 & 9,2797 & 58,2027 \\
\hline
\end{tabular}


Leite e Hein (2019)

Relação entre Remuneração dos Executivo e o Desempenho Econômico e Financeiro em Empresas Brasileiras

\begin{tabular}{|c|c|c|c|c|c|c|c|c|}
\hline $10^{\circ}$ & Localiza & 7,6767 & 12,6633 & 10,3046 & 9,1200 & 9,1303 & 9,2725 & 58,1673 \\
\hline $11^{\circ}$ & Kroton & 7,3031 & 13,1123 & 9,4141 & 8,7626 & 9,8597 & 9,7042 & 58,1561 \\
\hline $12^{\circ}$ & Braskem & 4,9268 & 9,8633 & 7,8091 & 14,2458 & 7,3969 & 13,6899 & 57,9319 \\
\hline $13^{\circ}$ & Estácio & 7,7912 & 11,8784 & 10,0281 & 8,5765 & 8,4460 & 9,9572 & 56,6772 \\
\hline $14^{\circ}$ & Sabesp & 8,9625 & 11,9186 & 7,7801 & 7,4444 & 9,8929 & 9,2522 & 55,2507 \\
\hline $15^{\circ}$ & Qualicorp & 6,2509 & 9,5604 & 8,8577 & 8,9037 & 10,1493 & 10,4643 & 54,1863 \\
\hline $16^{\circ}$ & Equatorial & 6,1326 & 9,4635 & 9,4697 & 8,6328 & 8,9987 & 9,8409 & 52,5383 \\
\hline $17^{\circ}$ & Hypera & 6,0675 & 9,8672 & 7,6408 & 7,9008 & 10,0796 & 10,0429 & 51,5987 \\
\hline $18^{\circ}$ & Cemig & 9,0935 & 12,4829 & 9,7334 & 7,9214 & 5,6411 & 6,6548 & 51,5271 \\
\hline $19^{\circ}$ & Telefônica Brasil & 7,4303 & 11,3325 & 9,8608 & 7,4299 & 7,4294 & 7,8174 & 51,3002 \\
\hline $20^{\circ}$ & BR Malls & 13,2039 & 12,3634 & 9,2331 & 6,7157 & 6,3075 & 1,5729 & 49,3966 \\
\hline $21^{\circ}$ & Klabin & 7,2379 & 9,9592 & 8,0768 & 6,9787 & 10,0142 & 6,9930 & 49,2598 \\
\hline $22^{\circ}$ & Cosan & 6,3292 & 9,6681 & 7,2819 & 7,5818 & 8,5041 & 9,0523 & 48,4175 \\
\hline $23^{\circ}$ & Magazine Luiza & 5,5936 & 10,3568 & 7,6133 & 5,8201 & 8,6413 & 10,1286 & 48,1537 \\
\hline $24^{\circ}$ & $\mathrm{BRF}$ & 6,4116 & 10,5376 & 9,8777 & 9,7247 & 6,2459 & 4,7309 & 47,5285 \\
\hline $25^{\circ}$ & MRV & 6,8345 & 10,2917 & 8,3990 & 7,3214 & 6,9290 & 7,7282 & 47,5038 \\
\hline $26^{\circ}$ & Pão de Açúcar & 7,2381 & 11,5875 & 9,8965 & 6,7790 & 3,9641 & 6,8265 & 46,2916 \\
\hline $27^{\circ}$ & Fibria & 4,6246 & 7,9693 & 7,0453 & 8,4127 & 8,4803 & 7,7645 & 44,2968 \\
\hline $28^{\circ}$ & Suzano Papel & 5,2309 & 8,6875 & 6,2181 & 7,0911 & 8,1512 & 8,8621 & 44,2409 \\
\hline $29^{\circ}$ & Embraer & 6,4857 & 10,3289 & 7,8278 & 7,0249 & 5,7256 & 6,5274 & 43,9203 \\
\hline $30^{\circ}$ & JBS & 5,7416 & 9,4569 & 7,2996 & 7,6748 & 5,8217 & 6,0352 & 42,0299 \\
\hline $31^{\circ}$ & Vale & 6,7598 & 9,2987 & 6,5747 & 2,4205 & 7,9798 & 8,9776 & 42,0109 \\
\hline $32^{\circ}$ & Siderúrgica Nacional & 5,2230 & 9,8620 & 6,4932 & 7,9831 & 4,8298 & 5,9985 & 40,3897 \\
\hline $33^{\circ}$ & Petrobrás & 6,4163 & 10,3799 & 4,7138 & 5,3071 & 4,3034 & 5,7061 & 36,8266 \\
\hline $34^{\circ}$ & Gerdau & 6,1301 & 9,8645 & 6,8800 & 4,8697 & 3,1925 & 5,3608 & 36,2977 \\
\hline $35^{\circ}$ & Usiminas & 4,9498 & 8,7900 & 6,2785 & 3,4882 & 3,8874 & 5,9423 & 33,3360 \\
\hline $36^{\circ}$ & Eletrobrás & 3,1151 & 5,3801 & 4,1046 & 2,2926 & 7,3694 & 4,6501 & 26,9118 \\
\hline
\end{tabular}

$\mathrm{Na}$ Tabela 3, se verificao rankingdas empresas a partir da distância $\mathrm{DP}_{2}$ de acordo com o desempenho econômico e financeiro no período de 2012 a 2017. No que tange ao posicionamento do ranking, a empresa Ambev foi a mais bem posicionada. Destaca-se que no ano de 2012 e 2013, a referida empresa estava na terceira posição do ranking, subindo para a segunda posição nos anos de 2014 e 2015, subindo novamente para a primeira posição em 2016 e por fim, voltando a terceira posição em 2017.

Na segunda posição do ranking geral, encontra-se a empresa Natura, cuja posição em 2012 foi a segunda, em 2013 e 2014 passou a ser a primeira do ranking, terceira em 2015, sexta em 2016 e quinta em 2017. No outro extremo do ranking, mais especificamente na última posição $\left(36^{\mathrm{a}}\right)$, encontra-se a empresa Eletrobrás. Sua colocação foi a última do ranking entre os anos de 2012 a 2015, passando a posição 25 em 2016 e indo para a 35 posição no ano de 2017.Assim pode-se estabelecer as posições das demais empresas analisadas.

Cabe destacar que empresas como Qualicorp, Equatorial, Hypera e Magazine Luizamelhoraram suas posições no ranking do início do período em relação ao final do período, enquanto as empresas Cemig e BR Malls pioram suas posições. Ressalta-se que este ranking aponta as empresas que apresentaram melhor performance econômica e financeira dentro do próprio grupo de análise a partir dos indicadores econômicos e de mercados, não indicase as empresas são mais ou menos eficientes, não sendo objeto deste estudo.

O último grupo de análise, se refere à relação entre a remuneração dos executivos e o desempenho econômico e financeiro das empresas brasileiras, sendo este o objetivo geral do presente estudo. Neste sentido, a Tabela 4 apresenta os resultados da regressão linear e da regressão quadrática da remuneração fixa.

Tabela 4 - Regressão Linear e Quadrática - Remuneração Fixa

\begin{tabular}{|c|c|c|c|c|c|c|}
\hline \multirow{2}{*}{ Variáveis } & \multicolumn{3}{|c|}{ Linear } & \multicolumn{3}{|c|}{ Quadrática } \\
\hline & Coef. & t test & Sig. & Coef. & t test & Sig. \\
\hline
\end{tabular}


Leite e Hein (2019)

Relação entre Remuneração dos Executivo e o Desempenho

Econômico e Financeiro em Empresas Brasileiras

\begin{tabular}{ccccccc}
\hline RFX & $-2,661$ & $-3,363$ & $0,001^{*}$ & 3,995 & 1,245 & 0,214 \\
RFX & & & $-6,458$ & $-2,140$ & $0,034^{* *}$ \\
CONS & 9,802 & 25,256 & $0,000^{*}$ & 8,425 & 11,235 & $0,000^{*}$ \\
R $^{2}$ & & 0,050 & & & 0,070 & \\
Sig. Modelo & & $0,001^{*}$ & & & $0,00^{*}$ \\
Nr. Observações & & & \multicolumn{2}{c}{216} \\
\hline
\end{tabular}

Legenda:RFX = Remuneração Fixa.*Significância ao nível de 1\%; **Significância ao nível de 5\%; ***Significância ao nível de $10 \%$.

Fonte: dados da pesquisa (2019).

Conforme na Tabela 4, tem-se como poder explicativo do modelo da regressão linearo $\mathrm{R}^{2}$ de 0,050 e, para o modelo de regressão quadrática, $\mathrm{R}^{2}$ de 0,070 (mais elevadopela inserção de uma variável adicional). Destaca-se que ambos os modelos apresentaram significativos ao nível de $1 \%$, o que valida a análise dos dados apresentados pelos respectivos modelos.É oportuno lembrar quea diferenciação entre o modelos é o termo de remuneração fixa elevado ao quadrado (segundo modelo) que visa identificar o nível do referido componente da remuneração executiva que maximiza o desempenho econômico e financeiro das organizações.

Quando analisado a relação entre a remuneração fixa (RFX) dos executivos e o desempenho econômico e financeiro pelo modelo de regressão linear, obteve-se coeficiente de $-2,661$, evidenciando uma relação negativa e estatisticamente significativa. Este resultado evidencia que quanto maior a remuneração fixa, menor o desempenho econômico e financeiro das organizações. Tal constatação diverge dos pressupostos da literatura, uma vez queo salário fixo é um importante componente da remuneração que atrai e retém talentos, e que, teoricamente, se reverte em desempenho superior. Tal fato pode estar relacionado com a tendência da maior ênfase na remuneração variável atrelada aos resultados da empresa (NASCIMENTO et al., 2013; ERMEL; MONTE, 2016).

Entretanto, quando analisado pelo modelo de regressão quadrática, o coeficiente da remuneração fixa (RFX) apresentou-se positivo $(+3,995)$, apesar de não significativo, enquanto o coeficiente quadrático $\left(\mathrm{RFX}^{2}\right)$ demonstrou-se negativo(-6,458)e significativo com o desempenho econômico e financeiro. Este resultado dá indícios de que há um ponto da remuneração fixa que maximiza o resultados da empresa e, após este ponto, o desempenho econômico se reduz, sendo este importante achado desta pesquisa. A tabela 5 apresenta a regressão linear e quadrática da remuneração variável de curto prazo.

Tabela 5 - Regressão Linear e Quadrática - Remuneração Variável de Curto Prazo

\begin{tabular}{|c|c|c|c|c|c|c|}
\hline \multirow{2}{*}{ Variáveis } & \multicolumn{3}{|c|}{ Linear } & \multicolumn{3}{|c|}{ Quadrática } \\
\hline & Coef. & t test & Sig. & Coef. & t test & Sig. \\
\hline RVCP & 3,300 & 3,453 & $0,001^{*}$ & 13,210 & 4,296 & $0,000^{*}$ \\
\hline $\mathrm{RVCP}^{2}$ & & & & $-13,661$ & $-3,382$ & $0,001^{*}$ \\
\hline CONS & 7,483 & 20,021 & $0,000 *$ & 6,125 & 11,292 & $0,000 *$ \\
\hline $\mathrm{R}^{2}$ & & 0,053 & & & 0,101 & \\
\hline Sig. Modelo & & $0,001^{*}$ & & & $0,000 *$ & \\
\hline Nr. Observações & & & & & & \\
\hline
\end{tabular}

Legenda:RVCP = Remuneração Variável de Curto Prazo. *Significância ao nível de 1\%; **Significância ao nível de 5\%; ***Significância ao nível de $10 \%$.

Fonte: dados da pesquisa (2019).

$\mathrm{Na}$ Tabela 5 se observa que o poder explicativo do modelo de regressão linearapresentou $R^{2}$ de 0,053 enquanto, no modelo de regressão quadrática, o $R^{2}$ foi de 0,101 , sendo ambos modelos estatisticamente significativos.O modelo de regressão linear apresentou, diferentemente da remuneração fixa (RFX), um coeficiente positivo $(+3,300)$ para a remuneração variável de curto prazo (RVCP), sendo este estatisticamente significativo, indicando que quanto maior a remuneração variável de curto prazo, maior o desempenho 
Leite e Hein (2019)

Relação entre Remuneração dos Executivo e o Desempenho

Econômico e Financeiro em Empresas Brasileiras

econômico e financeiro das organizações. Tal resultado corrobora com os pressupostos da literatura e com os achados dos estudos de Gonzaga et al. (2014) e Aguiar e Pimentel (2017), que destacam que a remuneração variável é um importante componente da remuneração que impactano resultado das organizações.

Quando analisado a regressão quadrática, se observa que o coeficiente da remuneração variável de curto prazo RVCP apresentou-se positivos, sendo ele de $+13,210$, enquanto o seu termo quadrático $\left(\mathrm{RVCP}^{2}\right)$ apresentou-se negativo, sendo de $-13,661$, ambos estatisticamente significativos. Estes coeficientes, assim como o observado na regressão quadrática da remuneração fixa (RFX) apresentada na Tabela 4, indica haver uma relação positiva entre a remuneração variável de curto prazo e o desempenho econômico e financeiro das organizações até um ponto ótimo de desempenho.

Isto significa dizer que, a remuneração variável contribui para com o desempenho econômico e financeiro até um certo ponto da curva, a partir daí, um aumento na remuneração variável implica em piora de tal performance. Outro ponto importante que se pode observar neste resultado é a força dos coeficientes da remuneração variável de curto prazo (RVCP e $\mathrm{RVCP}^{2}$ ) comparativamente aos encontrados na remuneração fixa (RFX), comprovando a força e importância deste componente de remuneração para com o desempenho econômico e financeiro das organizações analisadas. A Tabela 6 apresenta os resultados da regressão linear e quadrática da remuneração variável de longo prazo.

Tabela 6- Regressão Linear e Quadrática - Remuneração Variável de Longo Prazo

\begin{tabular}{ccccccc}
\hline Variáveis & Coef. & $\begin{array}{l}\text { Linear } \\
\text { t test }\end{array}$ & Sig. & Coef. & $\begin{array}{c}\text { Quadrática } \\
\text { t test }\end{array}$ & Sig. \\
\hline RVLP & 0,567 & 0,590 & 0,556 & 4,866 & 1,754 & $0,081^{* * *}$ \\
RVLP & & & & $-7,511$ & $-1,651$ & $0,100^{* * *}$ \\
CONS & 8,510 & 31,655 & $0,000^{*}$ & 8,187 & 24,674 & $0,000^{*}$ \\
R $^{2}$ & & 0,002 & & & 0,014 & \\
Sig. Modelo & & 0,556 & & & 0,217 \\
Nr. Observações & & & & 216 & & \\
\hline
\end{tabular}

Legenda: RVLP = Remuneração Variável de Longo Prazo.

*Significância ao nível de 1\%; **Significância ao nível de 5\%; ***Significância ao nível de $10 \%$.

Fonte: dados da pesquisa (2019).

Conforme a Tabela 6, o modelo de regressão linear apresentou $\mathrm{R}^{2}$ de 0,002 enquanto, no modelo de regressão quadrática, $\mathrm{o} \mathrm{R}^{2}$ foi de 0,014 , sendo que ambos os modelos não se apresentaram estatisticamente significativos. No entanto, é possível observar que no modelo de regressão linear, o coeficiente da remuneração de longo prazo apresentou-se positivo, mais especificamente de $+0,567$, indicando haver uma relação positiva com o desempenho econômico e financeiro das organizações.Já quando analisado a regressão quadrática, observa-se que o coeficiente da remuneração variável de longo prazo (RVLP) apresentou-se positivo $(+4,866)$ enquanto seu termo quadrático $\left(\operatorname{RVPL}^{2}\right)$ apresentou-se negativo $(-7,511)$, indicando que quanto maior este componente da remuneração, menor é o desempenho das organizações.

Este resultado é um importante achado pois dá indícios de que a remuneração de curto prazo (RVCP) exerce maior influência e tem maior poder explicativo para com o desempenho econômico e financeiro das organizações, fato não evidenciado pelos estudos anteriores.Por fim, a Tabela 7 apresenta os resultados da regressão linear e quadrática da remuneração total.

Tabela 7 - Regressão Linear e Quadrática - Remuneração Total

\begin{tabular}{ccccccc}
\hline Variáveis & \multicolumn{3}{c}{ Linear } & \multicolumn{3}{c}{ Quadrática } \\
& Coef. & t test & Sig. & Coef. & t test & Sig. \\
\hline RMT & 0,351 & 2,105 & $0,036^{* *}$ & 3,545 & 1,294 & 0,197 \\
RMT $^{2}$ & & & & $-0,099$ & $-1,168$ & 0,244 \\
\hline
\end{tabular}


Leite e Hein (2019)

Relação entre Remuneração dos Executivo e o Desempenho Econômico e Financeiro em Empresas Brasileiras

\begin{tabular}{|c|c|c|c|c|c|c|}
\hline CONS & 2,694 & 0,953 & 0,341 & $-22,868$ & $-1,037$ & 0,301 \\
\hline $\mathrm{R}^{2}$ & & 0,020 & & & 0,027 & \\
\hline Sig. Modelo & & $0,036 * *$ & & & $0,057 * * *$ & \\
\hline Nr. Observações & & & & & & \\
\hline
\end{tabular}

Legenda: RMT = Remuneração Total.*Significância ao nível de 1\%; **Significância ao nível de 5\%; ***Significância ao nível de $10 \%$.

Fonte: dados da pesquisa (2019).

Conforme a Tabela 7, o modelo da regressão linear apresentou $\mathrm{R}^{2}$ de 0,020 eo modelo de regressão quadráticaR ${ }^{2}$ de 0,027 , sendo de significância estatística de 5\% e $10 \%$ respectivamente. No modelo de regressão linear, a remuneração total (RMT) apresentou coeficiente de $+0,351$ com significância estatística ao nível de 5\%. Este resultado indica uma relação positiva e significativa com o desempenho econômico das empresas analisadas. Estes resultados são suportados pela literatura, uma vez que empresas que concedem melhores compensações aos seus executivos tendem a apresentar melhores desempenhos, sejam eles contábeis ou de mercado (GUIMARÃES; PEIXOTO, 2015). Neste sentido, pode-se inferir a utilização do sistema de remuneração dos executivos como um todopode estar alinhando os interesses dos agentes com o do principal.

Apesar de estatisticamente não significativo, na regressão quadrática o coeficiente da remuneração total (RMT) apresentou-se positivo, e o seu termo quadrático $\left(\mathrm{RMT}^{2}\right)$ negativo, indicando que há uma relação positiva entre a remuneração total dos executivos e o desempenho econômico e financeiro até um ponto ótimo, sendo que após este ponto, o desempenho das organizações analisadas decrescem. Para melhor visualização das relações entre os componentes da remuneração dos executivos e o desempenho econômico e financeiro das organizações analisadas por este estudo, apresenta-se a Figura 1. 
Leite e Hein (2019)

Relação entre Remuneração dos Executivo e o Desempenho

Econômico e Financeiro em Empresas Brasileiras

Figura1 - Regressão Linear e Quadrática da Remuneração dos Executivos

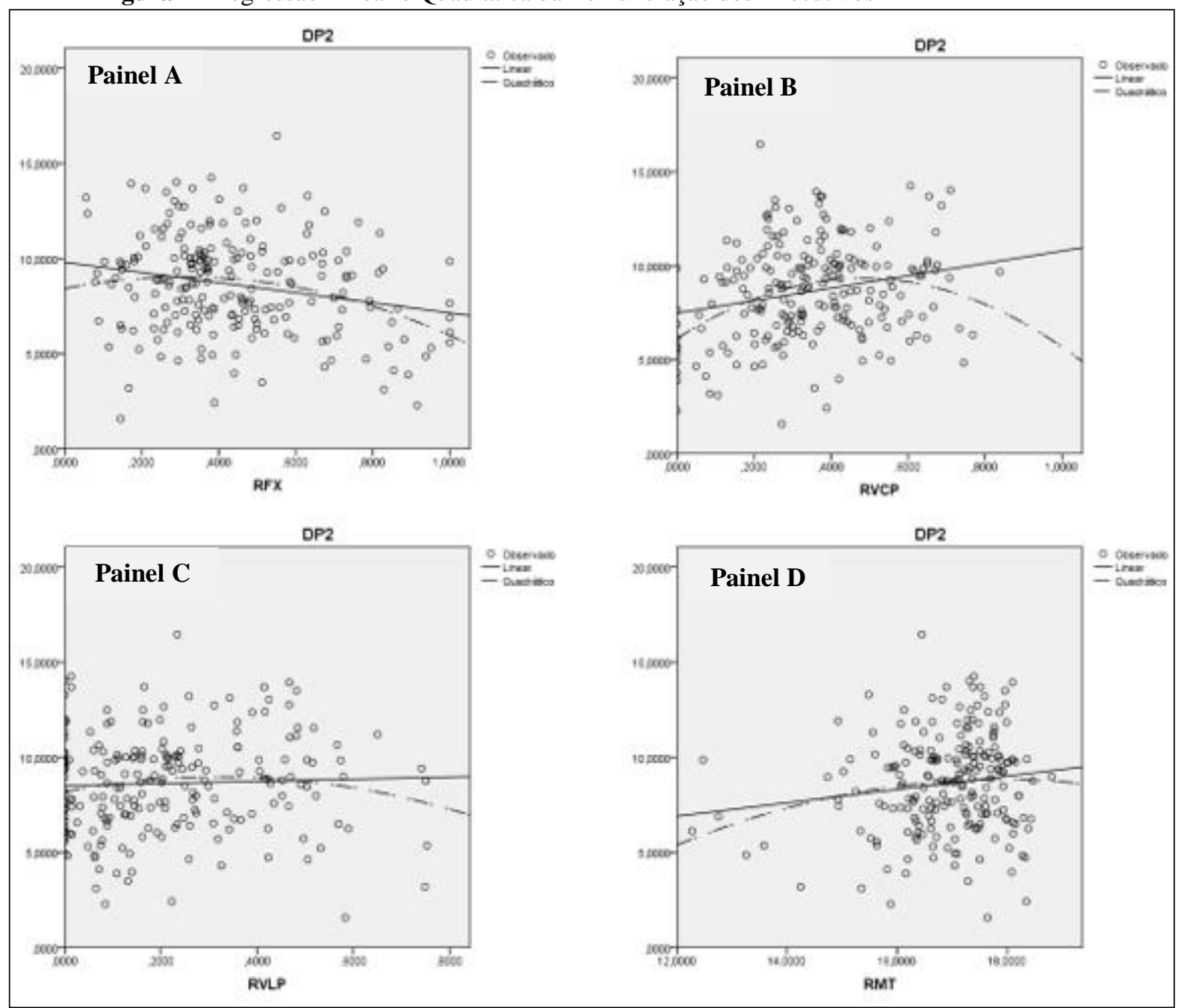

Legenda: RFX = Remuneração Fixa; RVCP = Remuneração Variável de Curto Prazo; RVLP = Remuneração Variável de Longo Prazo; RMT = Remuneração Total.

Fonte: dados da pesquisa (2019).

A Figura 1 apresenta os painéis "A", "B", "C" e "D" que apresentam respectivamente a relação da remuneração fixa $(\mathrm{RFX})$ dos executivos, a remuneração variável de curto prazo (RVCP), a remuneração variável de longo prazo (RVLP) e a remuneração total (RMT) com o desempenho econômico e financeiro $\left(\mathrm{DP}_{2}\right)$ das empresas brasileiras que compõem a amostra, por meio da regressão quadrática, no período de 2012 a 2017.

Em todos os painéis se observaque cada componente da remuneração executiva apresenta uma relação curvilínea em formato de "U Invertido", demonstrando que há uma relação positiva entre a remuneração dos executivos até um ponto ótimo de desempenho. Após este ponto, o desempenho econômico e financeiro apresenta-se decrescente.Com base nestas informações, pode-se constatar que, de forma geral, cada componente da remuneração possui uma relação distinta com o desempenho econômico e financeiro das organizações. Tais achados são importantes para a formação de um pacote de remuneração de forma que possibilite, além de satisfazer os interesses e as expectativas dos executivos e os interesses e expectativas dos detentores do capital, melhorar a performe econômica e financeira das organizações. 
Leite e Hein (2019)

Relação entre Remuneração dos Executivo e o Desempenho

Econômico e Financeiro em Empresas Brasileiras

\section{CONSIDERAÇÕES FINAIS}

A política de remuneração dos executivos têm despertado atenção literária em função da sua forte relação com a performance organizacional. De forma mais específica, têm-se que os modelos de remuneração, bem como outras formas de incentivos, sejam eles monetários e não monetários, ajudam a alinhar os interesses dos gestores com os interesses dos detentores do capital. Dessa forma, pressupõem-se que tal alinhamento de interesses impacta diretamente no desempenho econômico e financeiro das organizações.

Contudo, observou-se na literatura uma falta de consenso a respeito dos direcionadores de tal relação, sendo que enquanto estudos identificaram uma relação positiva (Silva; Chien, 2013; Gonzaga et al., 2014; Aguiar; Pimentel, 2017 e Souza et al., 2017), outros apresentaram relação negativa (Bradley, 2013 e Konraht et al., 2018). Tais divergências são comumente vinculadas à existência de uma variedade de elementos nos pacotes de remuneração, que consideram tanto os aspectos quantitativos quanto os aspectos qualitativos de desempenho (OBERHOLZER; BARNARD, 2015).

Estas constatações têm estimulado novas pesquisas, assim como o presente estudo, cujo objetivo foi analisar a relação entre a remuneração dos executivos e o desempenho econômico e financeiro em empresas brasileiras listadas na BM\&FBovespa. Para consecução de tal objetivo, procedeu-se uma pesquisa descritiva, com abordagem quantitativa, por meio de análise documental. A população da pesquisa compreendeu as empresas que compõe o IBRx50, tendo como amostra 36 empresas e com período de análise entre 2012 a 2017, o que totalizou 216 observações.

Os resultados demonstraram que há uma significativa modificação nos componentes da remuneração dos executivos, observando-se uma diminuição da remuneração fixa e um aumento na remuneração variável no período analisado. Sendo assim, é possível afirmar que o pacote de remuneração dos executivos está vinculada aos objetivos de desempenho das organizações. Quanto a relação entre a remuneração executiva e o desempenho econômico e financeiro, a regressão linear demonstrou que há uma relação negativa e significativa entre a remuneração fixa (RFX) e o desempenho econômico e financeiro. Com este resultado, é possível afirmar que quanto maior a remuneração fixa dos executivos, menor é a performance da organização. Este assertiva é corroborada pelo fato deste elemento da remuneração ter diminuído no período analisado.

Já em relação às remunerações variáveis de curo e longo prazos, os resultados demonstraram uma relação positiva e significativa com o desempenho econômico e financeiro. Cabe destacar que, por meio dos respectivos coeficientes, a remuneração de curto prazo possui uma relação mais intensa comparativamente a de longo prazo. Este é um importante achado pois estudos anteriores relacionados ao tema não fazem distinção entre as remunerações variáveis de curto e longo prazo. Também a remuneração total possui uma relação positiva e significativa com o desempenho econômico e financeiro das organizações analisadas.

Por outro lado, a regressão quadrática demonstrou que, todos os componentes da remuneração dos executivos (fixa, variável de curto prazo, variável de longo prazo etotal) apresentaram sinal positivo em seus coeficientesmas, quando elevados ao termo quadrático, seus sinais apresentaram-se negativos. Este resultado indica que a remuneração dos executivos tem uma relação positiva até um ponto específico de desempenho econômico e financeiro. Com isso é possível concluir que há um ponto ótimo de remuneração que maximiza o desempenho das organizações. 
Os resultados encontrados fornecem novos insigths sobre a relação entre remuneração executiva e desempenho econômico e financeiro das organizações que contribui, de forma prática e empírica, para a formulação de pacotes de remuneração dos executivos que estejam alinhados com os interesses das organizações, visando especialmente a maximização dos seus resultados.Este estudo diferencia-se dos demais pois utilizou de um método diferenciado na mensuração do desempenho econômico e financeiro das organizações, como é o caso da distância $\mathrm{DP}_{2}$ que, a partir da conjunção de diversas variáveis elabora-se um único indicador de desempenho. Já em relação à remuneração dos executivos, estudos tem classificado como remuneração fixa e variável, enquanto este estudo desdobra a remuneração variável em curto e longo prazo. Por fim, estudos têm-se utilizado de regressões lineares, a presente pesquisa inova trazendo para o contexto da remuneração dos executivos a regressão quadrática.

Destaca-se contudo, algumas limitações metodológicas do presente estudo que não permitem a generalização dos resultados alcançados. Primeiramente, tem-se que o estudo analisou somente o conjunto de empresas que compõem o IBRx50 que, apesar de terem grande representatividade de negociações no mercado de capitais brasileiro, pode trazer algum tipo de viés de amostra. Neste sentido, os resultados podem divergir quando analisados empresas que não pertençam a tal índice, ou então, quando analisado amostras maiores.

Outro fato importante é que, para a determinação do desempenho econômico e financeiro, utilizou-se apenas algumas das variáveis de desempenho econômico e de desempenho financeiro, dado a diversidade de outras variáveis disponíveis na literatura. Por fim, cabe reconhecer que as técnicas de análise utilizadas podem trazer vieses de interpretação, caso outras técnicas fossem utilizadas. Contudo, tais limitações não invalidam os resultados alcançados pela presente pesquisa.

Assim, sugere-se para pesquisas futuras a realização de análise com grupo de empresas além das analisadas por este estudo (IBRx50) a fim de verificar se a relação entre a remuneração dos executivos e o desempenho econômico e financeiro se comportam da mesma formaou na intensidade apresentada por este estudo. Ademais, é imprescindível acrescentar outras métricas de desempenho econômico e financeiros não analisados por este estudo, como por exemplo a utilização conjunta de métricas financeiras e não financeiras.

\section{REFERÊNCIAS}

AGUIAR, Andson Braga de; PIMENTEL, Renê Coppe. Remuneração de executivos e desempenho no mercado brasileiro: relações contemporâneas e defasadas. Revista de Administração Contemporânea, v. 21, n. 4, p. 545-568, 2017.

BM\&FBovespa - Bolsa de Valores de São Paulo. (2018). Disponível em:< http://www.bmfbovespa.com.br/pt_br/produtos/indices/indices-amplos/indice-brasil-50-ibrx50.htm>. Acesso: 10/05/2018.

BRADLEY, Samuel. The relationship between CEO compensation and company performance in a South African context. Journal of Economic and Financial Sciences, v. 6, n. 3, p. 539$564,2013$.

EDMANS, Alex; GABAIX, Xavier; JENTER, Dirk. Executive compensation: a survey of theory and evidence. In: The handbook of the economics of corporate governance. NorthHolland, p. 383-539, 2017. 
Leite e Hein (2019)

Relação entre Remuneração dos Executivo e o Desempenho

Econômico e Financeiro em Empresas Brasileiras

ERMEL, Marcelo; MONTE, Paulo Aguiar. Controle acionário, remuneração eexecutivos edesempenho empresarial: evidências para omercado brasileiro.Brazilian Review of Finance, v. 16, n. 3, p. 455-491, 2018.

FARMER, Mark A.; ALEXANDROU, George; ARCHBOLD, Stuart. New evidence of relative performance evaluation (RPE) in UK chief executive realised incentive compensation. Corporate Law:Corporate Governance eJournal, v.2, n.1, 2010.

GONG, James Jianxin. Examining shareholder value creation over CEO tenure: a new approach to testing effectiveness of executive compensation. Journal of Management Accounting Research, v. 23, n. 1, p. 1-28, 2011.

GUIMARÃES, Thayse Machado; PEIXOTO, Fernanda Maciel. A compensação dos gestores, a sustentabilidade empresarial e a performance das empresas brasileiras. Revista de Administração da UNIMEP, v. 13, n. 2, p. 186-212, 2015.

JENSEN, Michael C.; MECKLING, William H. Theory of the firm: managerial behavior, agency costs and ownership structure. Journal of Financial Economics, v. 3, n. 4, p. 305360, 1976.

KONRAHT, Jonatan Marlon; LUNKES, Rogério João; GASPARETTO, Valdirene; Schnorrenberger, Darci. Remuneração variável: um estudo da relação com indicadores financeiros das companhias abertas brasileiras. Revista Facultad de Ciencias Económicas: Investigación y Reflexión, v. 26, n. 1, p. 209-224, 2018.

MACHADO, Débora Gomes; BEUREN, Ilse Maria. Política de remuneração de executivos: um estudo em empresas industriais brasileiras, estadunidenses e inglesas. Gestão \& Regionalidade, v. 31, n. 92, 2015.

MURPHY, Kevin J. Incentives, learning, and compensation: a theoretical and empirical investigation of managerial labor contracts. The Rand Journal of Economics, v. 17, n. 1, p. 59-76, 1986.

MURPHY, Kevin J. Executive compensation. Handbook of labor economics, v. 3, p. 24852563, 1999.

NASCIMENTO, Eduardo Mendes; BARBOSA NETO, João Estevão; CUNHA, Jacqueline Veneroso Alves; DIAS, Warley de Oliveira Dias. Teoria da agência e remuneração de executivos: influência do uso de stock options no desempenho das empresas brasileiras.

Revista Iberoamericana de Contabilidad de Gestión, v. 11, n. 21, p. 1-16, 2013.

OBERHOLZER, Merwe; BARNARD, Jaco. Questioning the context of corporate performance measures in benchmarking CEO compensation. Corporate Ownership \& Control, v. 1, n. 13, p. 945-958, 2015.

OLIVA, Eduardo de Camargo; ALBUQUERQUE, Lindolfo Galvão. Sistema de remuneração de executivos e conselheiros como suporte à estrutura de governança corporativa. Revista Base (Administração e Contabilidade) da UNISINOS, v. 4, n. 1, p. 61-73, 2007.

SILVA, André Luiz Carvalhal; CHIEN, Alisson Chen Yi. Remuneração executiva, valor e desempenho das empresas brasileiras listadas. Revista Brasileira de Finanças, v. 11, n. 4, p. 481-502, 2013.

SOUZA, Paulo Vitor Souza; CARDOSO, Ricardo Lopes; VIEIRA, Simone Silva da Cunha. Determinantes da remuneração dos executivos e sua relação com o desempenho financeiro 
Relação entre Remuneração dos Executivo e o Desempenho

Econômico e Financeiro em Empresas Brasileiras

das companhias. REAd. Revista Eletrônica de Administração (Porto Alegre), v. 23, n. SPE, p. 4-28, 2017.

TINOCO, Paulo Paganoto; ROSSI, Gustavo Afonso Santi; PORTUGAL, Guilherme Teixeira. Remuneração dos executivos das companhias estatais e privadas de energia elétrica com maiores ativos listadas na BM\&FBOVESPA. Contabilidade, Gestão e Governança, v. 18, n. 3, 2015.

TRAPERO, Xesús B. Pena. Problemas de la medición del bienestar y conceptos afines:(una aplicación al caso español). Presidencia del Gobierno, Instituto Nacional de Estadística, 1977.

ZARZOSA, P. Aproximación a la medición Bienestar Social. España: Secretariado de Publicaciones de la Universidad de Valladolid. Recibido, v. 29, n. 10, p. 2010, 1996. 